\title{
Challenges and development directions of membrane bioreactors operated on passenger ships in international shipping
}

BIOOPEN 2021 - POST-CONFERENCE ARTICLE

\author{
KAROL TRZCIŃSKI (D, MAGDALENA ZIELIŃSKA (iD
}

University of Warmia and Mazury in Olsztyn, Faculty of Geoengineering, Department of Environmental Biotechnology, Słoneczna 45G, 10-709 Olsztyn, Poland

E-mail: karol.trzcinski@gmail.com

\begin{abstract}
In membrane bioreactor (MBR) technology, the activated sludge method is integrated with the separation of solid particles by ultrafiltration (UF). The technology ensures a high effluent quality, a shortened hydraulic retention time and a long sludge age that promotes slowly growing microorganisms and low sludge production. These advantages and the modular construction mean that MBRs have started to treat wastewater generated on passenger ships to adjust the treatment systems to the International Convention for the Prevention of Pollution from Ships. The aim of this paper is to present operational aspects of MBRs treating wastewater generated on ships, which are different from the aspects of MBR operation on land. This paper describes the consequences of separate treatment of gray wastewater (from showers, washing machines and kitchens) and black wastewater (from toilets), and of discontinuous flow of wastewater resulting from very high variability in the passenger number and the use of the MBR as a ship ballast element. The possibility of introducing a water recovery technology using the existing infrastructure on passenger ships as well as the hybrid UF/reverse osmosis technology is presented. The findings demonstrated that gray effluent may be reused for marine main engine cooling jackets of high and low temperature, ship boilers or ship laundry.
\end{abstract}

KEYWORDS: ultrafiltration, gray wastewater, black wastewater, water reuse

\section{Introduction}

In marine bioreactor (MBR) technology, wastewater treatment with the activated sludge method is integrated with the separation of solids in the membrane ultrafiltration (UF) module, which due to its function corresponds to the secondary settling tank. As a result of UF, permeate is released, directed to the treated wastewater tank, and retentate, that is, thickened activated sludge, is recirculated to the activated sludge chamber (Chiemchaisri et al. 1993, 
Goosen et al. 2005, Laurinonyte et al. 2017).

Compared to conventional systems with a secondary settling tank, the MBR technology has the following advantages: a high quality of treated wastewater, providing the basis for water renewal; a high concentration of biomass in the reactor, which allows shortening the wastewater retention time and even a threefold reduction in the cubature of the activated sludge chambers; a long sludge age that favours the growth of slowly growing microorganisms; and low excess sludge production, disinfection of wastewater, elimination of the secondary sedimentation tank, modular arrangement of membranes and reduction of the area required for the construction of the wastewater treatment plant (Chua et al. 2002, Lin et al. 2012, Fazal et al. 2015). The disadvantages of the system include contamination of membranes (fouling) and the requirement of a high aeration intensity.

The advantages of the MBR technology put it at the level of best available techniques (BAT) regarding wastewater treatment. The modular nature of an MBR system and other benefits of this technology have led to MBRs being used to treat wastewater from marine facilities. This use is related to the necessity to adjust the wastewater treatment systems to the applicable legal regulations.

Knowledge of the MBR technology is mainly related to onshore installations. The operation of MBRs on ships has distinct conditions compared with onshore systems, namely the separation of wastewater generated on the ship into black wastewater and gray wastewater. Separate treatment of gray and black wastewater streams with a highly efficient technology increases the flexibility of the system and the recycling potential of gray wastewater, which after treatment can be used, for example, for laundry. The efficient management of these separate streams and the ability to recover water are limited by another feature of the ship's installation: the discontinuity of the wastewater flow. The lack of continuity results from great variability in the number of people using the ship as well as from the fact that the MBR is used as a ballast element of the ship. Depending on the priority needs of maintaining stability, gray wastewater and permeate are kept in ballast tanks or released; hence, there is marked variability in the hydraulic load of the MBR installation, even leading to a shutdown of the installation. The objective of this paper is to indicate these operational aspects of MBRs used to treat wastewater generated on ships that distinguish them from onshore MBR systems.

\section{Legal regulations}

Wastewater and sludge management on board a ship is strictly regulated. The basic legal act regulating the discharge of wastewater into sea waters is the International Convention for the Prevention of Pollution from Ships (MARPOL), with its annexes and directives of the Maritime Environmental Protection Committee (MEPC) (MARPOL 73/78 1973/1978, MEPC.227(64) 2012). In addition, MARPOL regulates the provisions on special sea areas and particularly sensitive sea areas. For example, the Baltic Sea and the Baltic States are a special area with a categorical prohibition on the discharge of wastewater, regardless of the ship's location. Normal areas (except special areas) are open sea areas, outside territorial waters, more than 12 nautical miles from the coastline (MARPOL 73/78 1973/1978, MEPC.227(64) 2012). 
Annex 4 to MARPOL, introduced in 2003, states that outside of special areas (MARPOL 73/78 1973/1978):

- comminuted and disinfected wastewater (gray wastewater) may be discharged into the sea at a distance of more than 3 nautical miles from the coast,

- non-comminuted and non-disinfected wastewater (black wastewater) and excess sediment can be discharged into the sea at a distance of more than 12 nautical miles from the coast,

- in any event, the vessel must be traveling at a speed greater than 4 knots,

- irrespective of the ship's location, the wastewater treated in an efficient wastewater treatment plant can be discharged, as long as the wastewater will not cause visible solid particles to float in the water or change the colour of the water.

Annex 4 to MARPOL states that in special areas the discharge of wastewater is prohibited unless there is an efficient wastewater treatment plant on board the ship and the treated wastewater does not cause visible solid particles to float in the water or change the colour of the water. Moreover, additional manufacturer's requirements specified in the technical and operational documentation stipulate that the MBR installation may operate in special, particularly sensitive areas, as well as at a distance of less than 12 nautical miles, provided that the activated sludge is removed in the amount of $10 \%$ of the current content of the activated sludge chambers on the day of the planned stay in this zone, which is illustrated in the formula:

$$
10 \% \times \mathrm{m}^{3} \times \mathrm{d}=\mathrm{n}\left[\mathrm{m}^{3}\right]
$$

This means that depending on the number of days the ship spends in a given area, meeting the requirements of the installation manufacturer will have an impact on the operation of the MBR installation, for example, during a planned 14-day cruise on the Baltic Sea, where there is a total ban on discharge.

The presented requirements result in the necessity to adapt the MBR system operation to the geographical location of the ship, the number of days the ship stays in special areas, the variable load of the wastewater treatment plant with the load of pollutants resulting from different characteristics of gray and black wastewater and the variable hydraulic load of the installation resulting from the number of people and the use of wastewater for ballasting the ship.

\section{Description of the example installation}

The issues of the installation as well as the operational aspects have been described using the example of the real object of the advance wastewater treatment systems (MBR), which is operated on a ship that carries 100-3000 passengers.

The MBR installation (Figure 1) is adapted to work in three modes: with black wastewater, gray wastewater or a combination of both. There are two identical MBR installations on the ship. The discussed configuration is the only one of this type with dedicated treatment plants: the starboard MBR purifies gray wastewater and the port MBR purifies a mixture of gray and black wastewater. This solution increases ecological safety. Biological wastewater treatment is carried out in anoxic and aerobic chambers. The system also consists of a $500 \mathrm{~m}^{3}$ gray wastewater retention tank and four wastewater and ballast tanks with a volume of $500 \mathrm{~m}^{3}$ each. These tanks also receive permeate from the treated wastewater tank when the ship is in an area where discharge of wastewater is prohibited. The important fact that these tanks are used for ballasting the ship affects the hydraulic load of the MBR installation and the share of black 


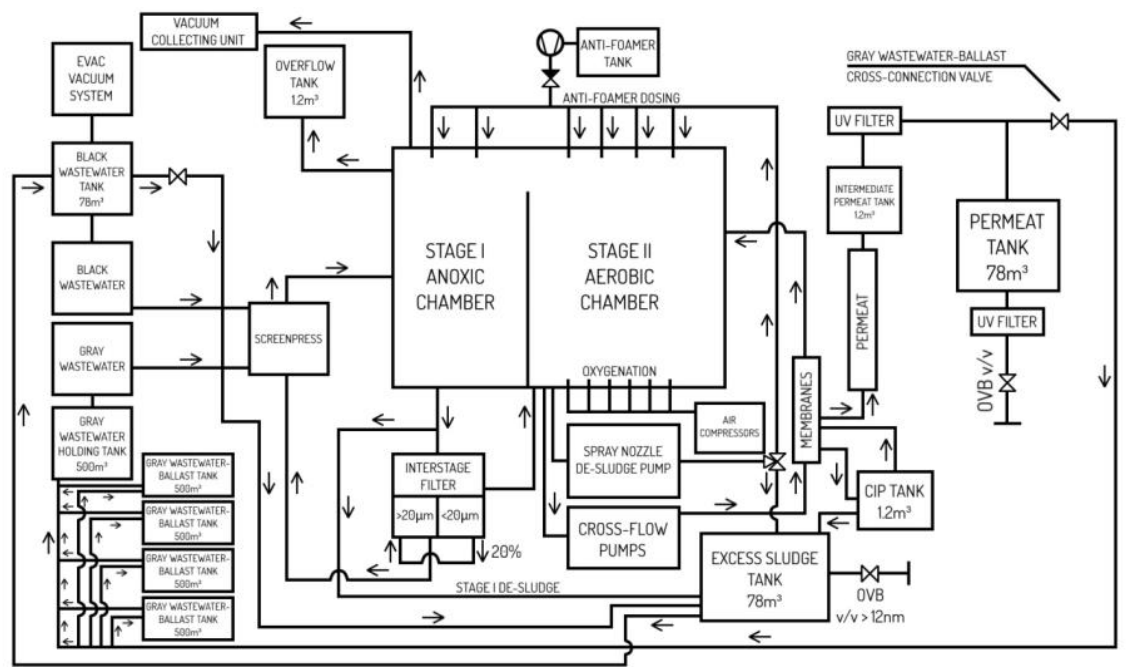

Figure 1. Scheme of the marine bioreactor (MBR) installation.

wastewater in the inflow to the installation. The share of black waste-water, in turn, influences the work of the interstage filter (ISF), which is a centrifugal separator with a capacity of $100 \mathrm{~m}^{3} / \mathrm{h}$. Wastewater and activated sludge from the anoxic chamber are directed to the oxygen chamber through this filter. The ISF separates solids from liquids: wastewater with a solid particle size $>20 \mu \mathrm{m}$ returns to the anoxic chamber and particles $<20 \mu \mathrm{m}$ go to the aerobic chamber. Wastewater with solids $>20$ $\mu \mathrm{m}$ can be diluted by wastewater with solids $<20 \mu \mathrm{m}$ to improve treatment. Optimisation of the waste-water flow procedure through the ISF chambers is important in the situation of a large share of black wastewater $(70 \%)$ with a high concentration of total suspended solids (TSS) of $200-500 \mathrm{mg} / \mathrm{l}$ in the inflow to the reactor. Moreover, the separation of particles on the ISF influences the size of the load of organic compounds in the wastewater introduced into the aerobic chamber, which deter-mines the nitrification. The membrane module with UF membranes is supplied from the activated sludge oxygen chamber.
The permeate goes to the $1.2 \mathrm{~m}^{3}$ treated wastewater tank, then to the $78 \mathrm{~m}^{3}$ treated wastewater tank and is discharged overboard or directed to the wastewaterballast system, depending on the ship's position and speed. Retentate - concentrated activated sludge - returns to the aerobic chamber. The number of days the ship is in special areas and the hydraulic load of the system affect the flow through the membranes and carry the risk of the membranes going into stand-by, causing the membranes to foul and reducing their hydraulic performance. The membranes are also equipped with a clean-in-place (CIP) system that includes $1.2 \mathrm{~m}^{3}$ membrane washing tank fed with service water that is produced by evaporators or reverse osmosis without using mineralisers. This water is used for closed-loop chemical rinsing as well as for backwashing, where each programmed open-loop cycle removes contaminants into the sludge tank and fills the rinsing tank once again. According to legal regulations, the excess sludge tank that collects excess sludge from the anoxic and aerobic chambers and technical water from the membrane 
washing tank can be emptied over 12 nautical miles at a speed of 6 knots. Moreover, it acts as an emergency in case there is wastewater leakage into the bilge. Due to these requirements, the operation of the tank affects the amount of activated sludge retained in the sludge chambers, which affects, among other things, the sludge age and the ability to provide the required oxygen concentration in the aerobic chamber.

\section{Development of the hybrid membrane technology}

The introduction of the hybrid membrane technology to passenger ships in international shipping should begin with a way to improve the MBR operation. This will enable water recovery as well as increase energy efficiency and reduce sulphur dioxide emissions to the atmosphere.

While maintaining the flow continuity, it is necessary to consider the problem of excess sludge. A single ship, in line with the operational recommendations, produces excess sludge on a daily basis as part of maintenance. To supply the MBR with excess sludge, we must analyse two options for implementing this solution, considering safety rules, compliance with environmental protection as well as applicable legal regulations. The first option is to include an excess tank to feed the black wastewater retention tank. Due to the specificity of wastewater systems on passenger ships, the black wastewater holding tank, depending on the periods of increased activity on board, often reaches the high-level limit, the reduction of which depends on the efficiency of wastewater treatment by the reactor. Accordingly, it might turn out that emptying the excess sludge tank would not be possible due to the overfilling of the black wastewater tank. Therefore, the possibility of water recycling could prove problematic. A more efficient solution would be to consider the use of excess sludge as a third source of MBR supply. This would allow the ship to maintain the continuous flow to the MBR and to reduce the discharge of excess sludge or even eliminate it altogether. In the case of a low level of gray wastewater in ballast tanks, a permeate tank could be used as another source of external recirculation water supply.

\section{Conclusions}

The last element regarding the MBR as a module of hybrid membrane technology is the connection of the reactor with the ballasting system, aimed at improving the gray wastewater treatment process regardless of the geographical location of the ship and the abandonment of the retention tank, replaced with a connection to all ballast tanks. To ensure the best possible operating parameters, including water recovery, reducing energy losses while maintaining compliance with environ-mental protection as well as in the interest of international water management, the UF/reverse osmosis (RO) hybrid membrane technology, based on the existing infrastructure of passenger ships, could be a step forward to water reclamation. The system uses the MBR unit as a pre-treatment, then the permeate is directed through a constant flow fabric filter and low-pressure pump to the RO unit. This solution will reduce the costs of the production of fresh water and could be used in marine power plant systems, as flash evaporators, used for fresh water production, require a specific engine load to increase the activity of the high-temperature water cooling jacket for effective desalination, which means more fuel burned to achieve the set point and also to reduce the cost of fresh water bunkers in ports. The efficiency of the process will not cause disturbances because the MBR and RO are designed 
for constant operation, and any stand-by periods can potentially increase membranes fouling. Therefore, it is necessary to ensure continuity of the flow.

Using the UF/RO hybrid membrane technology in shipbuilding will significantly reduce the environmental footprint and preserve the biodiversity of the seas and oceans while complying with international environmental law. The system will allow the maintenance of sustainable environmental development and set a new model of water management, focused mainly on water recovery. A similar system currently operates in Dubai's Burj Khalifa. The reclaimed water from the Dubai Mall and the Burj Khalifa supply the Dubai Fountain to make up the water lost to evaporation.

\section{References}

Chiemchaisri, C., Yamamoto, K., Vigneswaran, S. 1993. Household membrane bioreactor in domestic wastewater treatment. Water Science and Technology, 27(1): 171-178.

Chua, H.C., Arnot, T.C., Howell, J.A. 2002. Controlling fouling in membrane bioreactors operated with a variable throughput. Desalination, 149(1-3): 225-229.

Fazal, S., Zhang, B., Zhong, Z., Gao, L., Chen, X. 2015. Industrial wastewater treatment by using MBR (membrane bioreactor) paper study. Journal of Environmental Protection, 6(06): 584-598.

Goosen, M., Sablani, S., Al-Hinai, H., Al-Obeidani, S., Al-Belushi, R., Jackson, D. 2005. Fouling of reverse osmosis and ultrafiltration membranes: a critical paper. Separation Science and Technology, 39(10): 2261-2297.

Laurinonyte, J., Meulepas, R.J.W., van den Brink, P., Temmink, H. 2017. Membrane bioreactor (MBR) as alternative to a conventional activated sludge system followed by ultrafiltration (CAS-UF) for the treatment of Fischer-Tropsch reaction water from gas-toliquids industries. Water, Air \& Soil Pollution, 228: 137.

Lin, H., Gao, W., Meng, F., Liao, B.Q., Leung, K.T., Zhao, L., Chen, J., Hong, H. 2012. Membrane bioreactors for industrial wastewater treatment: a critical paper. Critical Papers in Environmental Science and Technology, 42(7): $677-740$.

MARPOL 73/78 International Convention for the Prevention of Pollution from Ships 1973/1978, Annex 4 Prevention of Pollution by Sewage from Ships 2003.

MEPC.227(64). International Maritime Organization, Maritime Environmental Protection Committee Resolution 2012. 